\author{
Andrés Botero Bernal \\ Universidad de Medellín, Colombia \\ botero39@gmail.com
}

\title{
Presupuestos epistemológicos y metodológicos de la iushistoria $^{1}$
}

\begin{abstract}
This article proposes and clarifies basic concepts for an understanding of iushistoria. First of all, it makes a distinction between iushistoria and the history of law. Secondly, it points out that iushistoria is a relatively autonomous juridical discipline as compared to general or professional historiography, which provides the first step for a dialogue between these two disciplines. Thirdly, it contends that the role of iushistoria is the memory of the juridical and of the jurist, which implies a constant dialog with dogmatic law. Fourthly, it posits that the method of iushistoria is fundamentally, yet not exclusively, the history of juridical texts in their immediate contexts; in other words, the historical documentary method. Fifthly, it reminds us of the importance of being attentive to the use of certain anachronisms. And, lastly, it suggests the use of the concept of "vital time and space", which would be very useful for historiography of law in Latin America.
\end{abstract}

Key words: Iushistoria, history of law, professional historiography, vital time and space, memory.

\section{Introducción}

El presente texto está basado en un trabajo inédito, de carácter descriptivo, sobre el estado del arte de la historiografía del derecho en América Latina. Ese estudio se realizó a principios del 2007 con el objetivo de conformar el Instituto Latinoamericano de Historia del Derecho (ILAHD). Se trató de un primer barrido de la cuestión, que deberá ser complementado, paulatinamente, por otros investigadores.

Con este trabajo tratamos de ofrecer algunas pautas de lo que, según nuestra investigación, podría ser una historiografía del derecho pertinente que, a su 
vez, fuese posible, especialmente (aunque no de manera exclusiva) en el marco latinoamericano, ya que, en esta región, los retos de la iushistoria son algo diferentes a los que deben afrontar los colegas europeos o norteamericanos, por citar sólo dos casos. En fin, se trata de una propuesta genérica para ser discutida en el seno del ILAHD.

El trabajo se divide en tres acápites, que responden a tres problemáticas concretas. El primero versa sobre las tensas relaciones entre la disciplina histórica y la disciplina jurídica en torno a la historia del derecho. El segundo aclara el objeto, la función y la finalidad que podría tener una historiografía del derecho pertinente y posible en el contexto latinoamericano. El tercero, y último, es una propuesta conceptual en torno a la iushistoria en nuestra región (el espaciotiempo vital) y una aclaración epistémica (los anacronismos).

Por último, tenemos que agradecer a los queridos colegas que han leído este trabajo y nos han dado sus comentarios y sugerencias, en especial a los profesores Eric Eduardo Palma (Universidad de Chile), Faustino Martínez (Universidad Complutense de Madrid), Andrea Macía Morillo (Universidad Autónoma de Madrid), Federico Escobar Córdoba (Universidad Javeriana, Cali) y Julián García (Universidad de Medellín), a quienes les estamos muy agradecidos por sus comentarios críticos y correcciones lingüísticas al presente texto. No obstante, la responsabilidad de lo aquí dicho recae exclusivamente en el autor.

\section{Derecho e historia o historia y derecho: una discusión en torno al carácter histórico o jurídico de la disciplina iushistórica}

Dentro de las principales discusiones que ha debido afrontar la historiografía del derecho en el escenario académico se encuentra la que ha centrado su interés en precisar la condición epistemológica de la disciplina; es decir, si se ha de asumir como una manifestación de la historiografía profesional ${ }^{2}$ ocupada del estudio de algunos asuntos de connotación jurídica o si, por el contrario, se ha de aprehender como el resultado de un análisis del pasado jurídico, desde y en función del discurso científico del derecho. En igual sentido, a la vez que importa determinar el carácter de la disciplina iushistórica, interesa establecer el tipo de formación necesaria para emprender estudios sobre la historia del derecho. En otras palabras, al igual que se discute si la iushistoria es esencialmente histórica, o si se enmarca en los contornos del derecho, del mismo modo se debate si el iushistoriador debe ser necesariamente historiador profesional, o si no es imprescindible que lo sea, asunto que, además, cabe plantearlo en vía contraria: iel iushistoriador debe ser licenciado en derecho?

En ese orden de ideas, con el fin de esclarecer las posibles relaciones subyacentes al encuentro de la historiografía profesional con la historiografía del derecho, debemos, antes que nada, dejar en claro los conceptos básicos que 
por un uso poco prudente han terminado por enmarañar aún más el escenario y con ello dificultar la resolución de los diferentes problemas epistémicos y metodológicos como el que acaba de presentarse.

De la misma manera como se diferencia historia (procesos pretéritos) con historiografía (interpretación de dichos procesos, interpretación que puede ser, entre otras posibilidades, profesional o disciplinaria), debemos diferenciar historia del derecho con historiografía del derecho o jurídica. Así, la historiografía jurídica es la interpretación de la historia del derecho, interpretación que si tiene el ribete de discurso disciplinario científico-jurídico denominaremos iushistoria. En consecuencia, el objeto de la iushistoria es la historia del derecho. Además, si queremos ser muy precisos, toda iushistoria es una historiografía jurídica, pero no toda historiografía jurídica es una iushistoria. Ahora bien, nos referiremos en este escrito fundamentalmente a la iushistoria, entendida pues como la disciplina jurídica que estudia (interpreta) la historia del derecho.

Agreguemos en este momento una explicación tanto para juristas como para historiadores. El término derecho es multifacético, por lo que su uso debe ser muy cuidadoso, puesto que con él podemos designar muchas cosas, como la disciplina científica que estudia un sistema normativo, o al mismo sistema normativo que determina lo legal/ilegal (en su sentido más amplio) en una sociedad concreta, entre otras posibilidades de significación. Para evitar malentendidos, en un texto que pretende dirigirse a un público amplio, designaremos aquí por "derecho" el sistema normativo (sin llegar a creer que sólo es norma la norma escrita). Cuando queramos referirnos a la disciplina, utilizaremos otras expresiones, tales como "Ciencia del derecho", "Disciplina jurídica", etc.

Ya aclarado lo anterior, pasemos a indagar por las relaciones entre la iushistoria y la historiografía profesional. Al respecto podemos, por lo menos, formular tres situaciones determinadas: ${ }^{3}$ en primer lugar, considerar la iushistoria como una parte integrante de la historiografía profesional; ${ }^{4}$ en segunda instancia, aislar completamente el estudio de la iushistoria de los campos disciplinarios comprendidos por la historiografía profesional; y, por último, pensar la historiografía profesional y la iushistoria de un modo recíproco, es decir, a partir de un paradigma interdisciplinario que se oriente a generar diálogos conjuntos en torno a un objeto determinado. ${ }^{5}$ Según la forma en que se aprehenda la relación entre ambas disciplinas, podrá hacerse referencia a tres escenarios: i) el de la sujeción disciplinaria (una por encima de la otra); ii) el de la comunicación inter pares fruto del reconocimiento de la autonomía de cada cual; y iii) el de la incomunicación si se parte del presupuesto de que ambas disciplinas se constituyen en esferas irreductibles (al que llamaremos "tesis aislacionista").

Sin embargo, pese a la claridad de cada una de las propuestas encaminadas a tratar la problemática de las relaciones entre la historiografía general y la iushistoria, es factible advertir en su formulación algunas deficiencias que dificultan 
aún más defender la tesis que promueve la fusión o, incluso, el distanciamiento radical entre ambos órdenes disciplinarios. En consecuencia, asumir la historiografía profesional y la iushistoria desde los lineamientos básicos de una tesis reduccionista (esto es, connotar la relación entre ambas bajo un paradigma de sujeción de una frente a la otra) implica perder de vista la autonomía relativa de ambas disciplinas y sus intereses legítimos para explicar de maneras diferentes situaciones jurídicas y socio-jurídicas que se forjaron en espacios-tiempos determinados o, en su caso, determinables. ${ }^{6}$ Ahora bien, compartir las ideas centrales de la tesis aislacionista supondría ignorar, al decir de Paolo Grossi, que el Derecho "no está escrito en un paisaje físico que espera aún una inserción humana, está escrito en la historia" (Grossi, 2003). Por tanto, pretender distanciar la iushistoria de la historiografía profesional traería, como efecto subsiguiente, la negación del tiempo (incluso del espacio) en la construcción (aunque no lineal) del derecho. ${ }^{7}$ En consecuencia, la propuesta de una iushistoria para el derecho sin contacto alguno con la historiografía profesional es igual o más excesiva que una iushistoria del derecho pensada exclusivamente desde y para la historiografía profesional.

Finalmente, si bien parece necesario afirmar la autonomía relativa de ambas disciplinas -iushistoria e historiografía-, asunto que se defenderá más adelante, no es posible compartir con igual certeza la idea de su radical separación. Por tanto, con el fin de guardar la correspondencia entre la historiografía profesional y la iushistoria (eso sí, sin llegar a confundirlas), debemos aprehender su relación a partir de la diferencia y en función de un diálogo interdisciplinario puesto que sólo así podría darse cuenta del derecho entendido éste como un fenómeno cultural (Lattore, 1985; Córdoba, 2008; Villegas, 2009), en la medida que el derecho (y su historia) no es, ni puede ser, un objeto exclusivo del discurso jurídico (lo que legitima completamente que el derecho -y su historia- sea objeto de estudio de otras disciplinas científicas) y que lo jurídico no se agota en el Estado. ${ }^{8}$ De esta forma, será el objeto -su naturaleza- el que determine la necesidad de conjugar éstas y otras disciplinas con el fin de facilitar la labor del iushistoriador que precise acudir al contexto amplio (que está mejor soportado en la historiografía profesional), o bien, la del historiador profesional que debe aproximarse al "ser jurídico" (pormenorizado de mejor manera por el iushistoriador jurista) para comprender -lo que supone describir y explicar- el "campo" en su estructura macro. En esencia, se trata de acoger el modelo (paradigma) de la complejidad ${ }^{9}$ para ilustrar la forma en que deben acercarse la historiografía profesional y la iushistoria en la intención conjunta de comprender, de la manera más integral posible, un objeto determinado que requiere, por lo menos, de ambos enfoques -sustancialmente distintos, aunque en ningún caso irreconciliables- para una explicación suficientemente compleja y en mayor medida completa. 
En ese sentido, para que pueda establecerse una relación entre la iushistoria y la historiografía profesional, una y otra deben reconocerse como disciplinas autónomas relativamente, con objeto y métodos más o menos propios (aunque en ningún momento únicos) y con funciones distintas; es decir, con formas de actuar diferenciables que permitan vislumbrar el encuentro entre el "ser histórico" y el "ser jurídico" en el desarrollo de estudios historiográficos o de condición iushistoriográfica. De esta forma, si se quiere comprender en su complejidad un fenómeno cultural común (como lo es el derecho), se tiene que reconocer la interdependencia de las disciplinas para lograr tal cometido y -si éstas previamente se reconocen como tales y, por tanto, se legitiman para el diálogo fraterno- se allana el camino para la interdisciplinariedad, tal como lo explica Villegas:

[L]a interdisciplinariedad debe entenderse como una herramienta para facilitar diálogos disciplinares, pero de ninguna forma significa la anulación o el desconocimiento de las características propias de las distintas áreas del conocimiento (Villegas, 2009 : 3-22)

También tenemos las palabras de Zorraquín Becú, quien insiste -a nuestro modo de ver- en la necesidad de encuentros epistemológicos de naturaleza relativa (desde el objeto y a partir de él) y no jerárquica, entre la disciplina jurídica y la historiografía:

La historia del derecho es historia por su método y es derecho por su objeto [...] No olvidemos que en nuestra materia [...] tanto la historia como el derecho son dos ciencias que si bien tienen métodos y objetivos diferentes, se conjugan en una sola aportándole algo que es propio de cada una (Zorraquín, 1978).

Sin intención de condensar en pocas líneas la problemática alusiva al carácter epistemológico de la iushistoria, es preciso indicar que, entre los más destacados representantes de la tesis que niega o pone bajo sospecha (según cada caso) la autonomía de la iushistoria con respecto a la historiografía profesional, encontramos a Eduardo de Hinojosa, Tomás y Valiente (Zorraquín, 1978) ${ }^{10} \mathrm{~J}$. M. Pérez-Prendes (quien considera que la iushistoria sólo puede aprehenderse dentro de la historia general-total), (Tomás y Valiente, 2001) ${ }^{11}$ y Emilio Lecuona, entre otros. Entre ellos, merece resaltar la reflexión que el profesor Emilio Lecuona hace del carácter historiográfico de la iushistoria:

Esta cuestión, que a priori parece sencilla de resolver, pues es evidente que la Historia del Derecho es una especialidad histórica, es, sin embargo, una de las cuestiones que en general han sido más descuidadas por los historiadores del derecho, no 
sólo norteamericanos. El hecho de que la Historia Jurídica como disciplina claramente delimitada en la Contemporaneidad se haya desarrollado fundamentalmente por juristas en el entorno de la Ciencia del Derecho, ha provocado que éstos hayan siempre tratado de justificar su actividad para esta ciencia en lugar de para la histórica, de manera que por ejemplo se ha insistido constantemente en la utilidad de ella para los juristas e incluso se ha pedido su entrada en el currículo de los estudios de Derecho, mientras que se ha insistido poco o nada en su utilidad para los historiadores. Todo lo cual ha implicado un alejamiento general entre historiadores e historiadores del derecho que en países como Estados Unidos, donde se desarrolló en un primer momento una Historia Jurídica totalmente volcada a los juristas y a la práctica de los Tribunales, se convirtió, como ya se indicó anteriormente, en un auténtico abismo entre ellos. ${ }^{12}$

Igualmente, está el trabajo del profesor Palma, quien señala:

¿Es posible que una investigación que se ocupa del pasado no sea historiografía?, o, dicho de otro modo, que una investigación histórico-jurídica siga siendo derecho y no historia. Nos parece que no [...] Resulta de suma relevancia para la investigación históricojurídica que lo estudiado tenga proyección en el tiempo, porque es el estudio de la proyección temporal lo que transforma dicha investigación en histórica [...] En la perspectiva polifacética la disciplina histórico-jurídica es histórica, por lo mismo se ocupa de la dimensión temporal del derecho. Lo que le interesa es su historicidad no su derogabilidad. No es un factor de carácter estrictamente jurídico lo que determina su objeto de estudio, sino su calificación como fenómeno histórico (Palma, 1997). ${ }^{13}$

Por el contrario, fortalecen los esfuerzos teóricos de las tesis aislacionistas (en algunos casos) o diferenciadoras (en otros), los aportes de Jesús Lalinde, José Antonio Escudero, Carlos Petit, Bartolomé Clavero y, con mayor fuerza, los de Alfonso García-Gallo. Dice así este último:

El Derecho es una ordenación de la vida social que posee fuerza vinculante. Es sólo una ordenación, no la vida social misma en toda su complejidad; esto independientemente de la importancia que aquélla pueda tener para ésta. El objeto de la ciencia de la Historia del Derecho debe limitarse sólo a aquella ordenación sin pretender abarcar la vida social, que en su conjunto o en sus particulares manifestaciones constituye el objeto de otras ciencias. [...] El derecho constituye, sin duda, un aspecto de la cultura global de la sociedad, 
pero con la suficiente entidad para poder ser objeto de estudio en sí mismo; como lo son también la religión, el lenguaje, el arte, etc. (García-Rayo, 1971) ${ }^{14}$

Sin embargo, como una propuesta alternativa a las dos enunciadas con anterioridad, se ha tratado de advertir en la iushistoria un fundamento histórico y, al mismo tiempo, un fundamento jurídico. En ese sentido, la iushistoria se presenta como una disciplina que vuelve la mirada al pasado, para tratar, por mediación de la fuentes, algunas situaciones jurídicas que identificaron el derecho en espacios-tiempos vitales específicos, todo ello con el fin de preservar la memoria del jurista, la memoria de lo que fue -independientemente de que siga siendo- considerado derecho y la memoria de la disciplina jurídica misma.

No obstante, lo anterior exige dos aclaraciones. La primera es que no se niega así una conexión con la historiografía profesional, aunque tal conexión se mantenga sólo de un modo relativo; es decir, mientras la historiografía profesional regresa al pasado para crear discurso, la iushistoria lo hace para recrear, para reconstruir una memoria. En otras palabras, la iushistoria, si bien funda buena parte de sus estudios sobre la base histórica de la historiografía profesional, lo que pretende es recordar fundamentalmente a sus colegas juristas dogmáticos las condiciones históricas del "ser jurídico". La segunda aclaración es en torno al concepto de memoria; al respecto, escribe el profesor Carlos Petit:

[L]a razón mejor que hoy justifica la presencia de la historia jurídica en los estudios universitarios se encuentra en el cultivo y desarrollo de la llamada memoria del jurista, expresión comprometida que entiendo, provisionalmente, como la tradición "disciplinar" del derecho y de los que socialmente se identifican como sus expertos [...] en este sentido, no sería el Derecho -presente o pasado- el principal objeto de observación, sino todo aquello que, a propósito del derecho, han podido decir y escribir personas insertas en ciertas instituciones (tribunales, universidades, parlamentos) encargadas de la producción de textos de reputados jurídicos: en otros términos, habría que averiguar qué hace que tengamos por especializados (escritos, discursos, personas) a los que, cumplidos ciertos requisitos, así se consideran (Pettit, 2005). ${ }^{15}$

Siguiendo con esta corriente alterna merecen ser destacados los aportes de Luís García de Valdeavellano:

[E]n cuya obra se aprecian ya hacia 1939 las tensiones que empiezan a aparecer en la Escuela de Hinojosa. Él se hace eco de tres problemas más frecuentes planteados en la producción histórico-jurídica del momento: su posicionamiento en la línea de la dogmática jurídica; 
su consideración de la naturaleza mixta de la Historia del Derecho, que es ciencia histórica y ciencia jurídica y su distanciamiento de la postura inicial de la escuela de Hinojosa, optando por la separación de la Historia de las Instituciones y la Historia del Derecho (Moran, 1999: 36).

Resumiendo, tanto la historiografía profesional como la iushistoria se ocupan de un mismo objeto: el pasado (general para el primero, específico -pasado jurídico- para el segundo); pero, en el caso de lo jurídico, no puede confundirse lo pretérito con lo derogado, puesto que el derecho vigente tiene un pasado, una dimensión temporal, que es (y debe ser) objeto de estudio del iushistoriador y una excelente oportunidad para dialogar con el jurista dogmático.

Ahora bien, una y otra se escinden cuando desarrollan su labor en torno a un objeto especial, cualificado, específico: lo histórico o lo jurídico. Por tanto, si la historiografía profesional se ocupa, como debe ocuparse, del derecho, lo hará dentro un sistema complejo, modelador de relaciones en contextos más amplios y con una función diferente. Por su parte, la iushistoria lo abstraerá de esa esfera macro para analizarlo en sí, de conformidad con el (con) texto (más jurídico posible), y siempre en función suya. Es así como el derecho, por su condición pretérita, puede y debe ser estudiado (entre otras disciplinas) tanto por la historiografía profesional como por la iushistoria; una diferencia radica en el lugar que este ocupa en el desarrollo de los mismos y, a su vez, en la especificidad y el lenguaje de los resultados que una y otra presentan cuando se aproximan a lo jurídico. Esto hace que el historiador, de frente al problema que lo ocupa, tienda a un empleo poco estricto de los términos jurídicos, pero a un uso más preciso de los términos del contexto socio-histórico; asimismo, el historiador centra su estudio en las relaciones contextuales de una forma general (en donde el derecho funge como otra esfera de acción social que debe implicarse con otros fenómenos que explora), mientras que el iushistoriador, puesto en ese marco de relaciones contextuales, fijará su atención en el estudio de aquello que ataña al derecho o que, al menos, suponga una invocación de lo jurídico, es decir, con trascendencia a él, para construir así una memoria. En otros términos, mientras el historiador es contextual, el iushistoriador es más textual, si se le compara con aquel; sin embargo, el iushistoriador es más contextual si se compara con el dogmático jurista. El iushistoriador es, entonces, un mediador entre la contextualidad socio-histórica del historiador profesional y la textualidad jurídica del dogmático.

De esta forma, el objeto de la iushistoria lo constituye el "ser jurídico" -que repetimos no es exclusivamente normativo y no es solamente estatal- ${ }^{16}$ a través del tiempo; es decir, aquello que fue memoria del jurista y de lo jurídico (lo que no significa que sólo se estudie lo derogado) en contextos temporal y espacialmente definidos. Por esto, la labor del iushistoriador, en su fase técnica, se asimila a un 
"proceso arqueológico"17 que se inicia con la búsqueda de las fuentes, continúa con la depuración de las mismas y finaliza con la comprensión de lo estudiado: encuentro sucesivo, progresivo e inquietante.

Pero reconocer estos rasgos diferenciadores (no necesariamente epistemológicos) del iushistoriador y de la iushistoria no implica una invitación al aislacionismo disciplinario, en la medida que urge, para la buena comprensión del ser jurídico, un diálogo con otras disciplinas, especialmente con la historiografía profesional, con la sociología y con los dogmáticos del derecho vigente, entre otras. No se invita a la fragmentación, sino al reconocimiento de la diferencia para construir conjuntamente. Es decir, a la fraternidad entre disciplinas como requisito para la interdisciplinariedad desde y hacia lo jurídico (Escobar, 2008).

\title{
Objeto, función y finalidad de la iushistoria del derecho: una reflexión en torno a sus fundamentos básicos
}

\begin{abstract}
El historiador del derecho no puede ser totalmente imparcial; de hecho debe ser crítico más que ningún otro, pues tiene delante no sólo una época, sino el nacimiento, desarrollo y crisis del mismo derecho. Además la historia tiene algo de vivo, algo que se proyecta al futuro con base en el análisis del pasado.
\end{abstract}

José Ramón Narváez Hernández

Admitir el carácter autónomo (aunque no desconectado) de la iuishistoria, y, en consecuencia, afirmar su independencia disciplinaria respecto de la historiografía profesional -es decir, reconocer su connotación jurídica antes que meramente histórica- conduce necesariamente al interrogante sobre los fundamentos esenciales que deben identificar la iushistoria como disciplina distinta -aunque no por eso inconciliable- de la historiografía profesional. En ese sentido, no se trata solamente de defender la autonomía de la iushistoria sobre la base de intereses académicos que carecen de justificación alguna. Por el contrario, se trata de identificar en la iushistoria un conjunto de elementos -en este caso esencialmente epistemológicos y de sociología de la ciencia- que definen el oficio del iushistoriador, así como las especiales características que individualizan su campo de estudio.

Es así como deben señalarse las preocupaciones (objeto), los compromisos (funciones), el horizonte de proyección (finalidad) y los escenarios concretos de trabajo (estructura) de la disciplina histórico-jurídica. En ese orden de ideas, mirar al objeto implica delimitar los asuntos de los que debe ocuparse la iushistoria. Detenerse en sus funciones supone precisar el tipo de labor que desarrolla la iushistoria en el interior de la disciplina jurídica. Reparar en su finalidad sugiere la necesidad de demarcar el escenario teleológico que subyace a los 
estudios en iushistoria. Finalmente, denotar la estructura implica reconocer los límites de cualquier observación, además de permitir ratificar con ello que toda reflexión supone una red que interconecta tanto elementos simbólicos como materiales (Capra, 2007). La comunicación entre los conceptos precedentes (objeto, función, finalidad y estructura) integra el fundamento básico de la iushistoria y el punto de partida para seguir puliendo la iushistoria que, sobre la historia del derecho, se hace en el taller del iushistoriador, con la ayuda de los instrumentos necesarios para hacer de sus tenues trazos la obra que concentre su más notable esfuerzo.

En consecuencia, la iushistoria se preocupa por estudiar el pasado desde la dimensión más jurídica posible pero sin llegar a la textualidad del dogmático jurista. En otras palabras, en tanto que la historiografía profesional regresa al pasado para estudiarlo en su textura abierta (dentro de la cual interpreta lo jurídico desde contextos socio-históricos amplios), la iushistoria del derecho regresa a cierto pasado construido por ella misma (a la que denomina "pasado jurídico") con el fin de conferirle un tratamiento más especializado, y por consiguiente, mucho más concentrado en su especial objeto de estudio. Como diferencia adicional, debe decirse que la iushistoria, esencialmente, es una historiografía que, sin desconocer el espacio, proyecta el entorno jurídico desde el texto jurídico; es una historiografía de límites, o bien, de posibilidades. Una historiografía, finalmente, que circunscribe los esfuerzos del iushistoriador en la aprehensión del texto (más que del contexto amplio, si se mira desde el lente del historiador profesional) y del contexto (más que de lo normativo-texto legal, si se mira desde el lente del dogmático jurista) jurídicos.

Esta diferencia en la forma de emprender el análisis del objeto -es decir, desde lo general para el historiador o desde lo específico para el iushistoriador (con énfasis en el complejo jurídico)-, ha hecho que los resultados del primero sean tenidos por superficiales o generalistas, mientras que los del segundo se califiquen de reduccionistas. Sin intención de fortalecer esa discusión en calificativos -que más pareciera preocuparle el interés por resaltar limitaciones desde un enfoque despectivo-, debe indicarse que el esfuerzo de la iushistoria se manifiesta en la preocupación por permitirle al derecho, al jurista y a la disciplina jurídica, una identidad que se corresponda con las circunstancias específicas que los circundan, condicionan y definen $;{ }^{18}$ situación que, al mismo tiempo, nos induce a pensar en las relaciones conflictivas entre la ciencia del derecho y la iushistoria, y en las consecuencias nocivas de su incomunicabilidad. Al respecto escribimos en otro lugar:

La poca comunicabilidad de los resultados investigativos entre la Historia del Derecho con el derecho mismo, (ha hecho que) este último se aleje más del cometido que debiera tener: conocer su pasado, para comprender el presente y proyectarse a futuro, dentro 
de un escenario científico-crítico (Botero, 2006: 13-14).

En función de esto, la inquietud por la historia del Derecho es la inquietud por la identidad de lo jurídico (en un sentido amplio) y, del mismo modo, la preocupación por dotar de sentido a un conjunto de expresiones culturales con notable proyección jurídica. En consecuencia, sólo mediante la historiografía jurídica (como memoria del Derecho, de la disciplina jurídica y del jurista) será posible develar la fisonomía del Derecho en los oscuros pliegues de un texto que corresponde iluminar al iushistoriador. El derecho pasado -lo que se reputó como tal- está condensado, fundamentalmente, en los textos considerados en su momento como jurídicos, salvo, claro está, aquellos períodos en que el iushistoriador puede y debe auxiliarse de la arqueología y de otras disciplinas ante la ausencia o ante la estrechez de las fuentes escritas. Así las cosas, el texto jurídico (que no se limita a la norma escrita), a pesar de su vaguedad, es el objeto central -aunque no exclusivo, dependiendo del caso- ${ }^{19}$ del análisis iushistórico, que lo contextualiza, sin mediatizarlo. El texto, para la mayoría de los historiadores, es un medio de acercamiento a una realidad esquiva que se pretende atrapar mediante la interpretación. En cambio, para el iushistoriador, el texto debe ser, en principio, la realidad misma que desea hacer parte de la memoria colectiva de la disciplina jurídica. ${ }^{20}$ Por tanto, el derecho, en su conjunto textual que no excluye el contexto social que da vida al texto, necesita ser aplicado y comprendido históricamente.

Del mismo modo, al igual que se hace un examen detenido acerca del objeto de la iushistoria, debe precisarse, correlativamente, la función que debe cumplir como disciplina autónoma, de estricta condición jurídica y en comunicación con la historiografía profesional. De conformidad con esto, la justificación de la iushistoria, así como la de la necesidad de su impulso en el ámbito académico y en especial en las facultades de Derecho, debe orientarse desde la función que está llamada a cumplir dentro del entorno jurídico. En términos de Paolo Grossi, se hablaría de una iushistoria dispuesta a ser la "conciencia crítica" del derecho y de su disciplina científica (Narvaez, et al. 2003). En palabras de António Manuel Hespanha, se aludiría a una iushistoria capaz de "problematizar o pressuposto implícito e acrítico das disciplinas dogmáticas” (Hespanha; 2005 : 21). Finalmente, en concepto de Tomás y Valiente -seguidor de la hermosa frase de Kohler-, la iushistoria debe fundarse en la iusfilosofía como presupuesto inescindible de su reflexión (Tomás y Valiente, 2001 : 29). En consecuencia, la función de la iushistoria es la de ser una disciplina crítica, interesada en fortalecer la memoria de lo jurídico (en sentido amplio), fundada en el análisis del (con) texto ${ }^{21}$ reconociendo la contingencia de las situaciones jurídicas y ocupada en devolver al derecho y a su disciplina la identidad que hubo de sepultar en mitos de continuidad o de progreso lineal, ${ }^{22}$ pero sin caer, igualmente, en las 
tentaciones de explicar el Derecho a partir de dicotomías irreductibles, fruto de supuestas rupturas totales. ${ }^{23}$

Ahora bien, por la connotación de "crítica" que debe cualificar a la iushistoria, no puede desconocerse la función descriptiva que, en algunos casos, se orienta a cumplir la disciplina iushistórica. Sin embargo, se considera que una iushistoria crítica debe ser, al mismo tiempo, una iushistoria descriptiva; en otras palabras, podría afirmarse que el presupuesto de la crítica es partir de una correcta descripción y análisis del fenómeno histórico jurídico que se piensa analizar. Por tanto, preferimos el enfoque que acaba de explicarse, antes que el esquema simplemente descriptivo (que conlleva una exaltación del documento más allá de lo razonable y una falta de análisis en las lecturas realizadas), en el que, a veces, se pretende sumir la iushistoria. En síntesis, la aproximación al objeto de estudio podrá efectuarse desde dos enfoques: uno descriptivo, centrado en la simple enunciación del texto jurídico a partir de las fuentes primarias, y otro crítico, interesado, además, en efectuar una valoración jurídica del objeto analizado, para lo que se requiere una previa descripción. Optamos por el segundo enfoque.

De esta forma, la iushistoria empieza a perfilarse como un instrumento de interpretación jurídica; es decir, permite la asunción del derecho a través de coordenadas espacio-temporales que informan de sus cambios, en últimas, de su proceso constructivo a través de los (con)textos. Esa lectura histórica del derecho es promotora de la integridad, de la fidelidad y de la precisión; coadyuva en la formación de la dimensión reflexiva que debe tener la ciencia jurídica. En palabras de Narváez representa la propuesta "de crear en la ciencia jurídica una conciencia crítica que nos lleve a concebir el derecho en todos sus sentidos, a intuirlo en la problemática cotidiana, a descubrirlo en la sociedad y a entenderlo a través de su realidad histórica, política y conceptual" (Narváez, 2007 : 18). Esto permite recordar que el derecho es, por esencia, un producto (proyecto) cultural, como ya se dijo. Se infiere, así, que el derecho es, al mismo tiempo, un proyecto histórico: el derecho pasado y también la iushistoria responden a causas concretas y específicas. Estas causas solo podrán develarse con la ayuda de una forma de reflexión que indague sobre los presupuestos últimos del cambio (la pregunta por la razón, la esencia del devenir), con la ayuda, finalmente, de una especie de filosofía de la Historia del Derecho y de la iushistoria.

Finalmente, como último de los fundamentos básicos que caracterizan la iushistoria, debe hacerse referencia a la finalidad de sus estudios con el ánimo de determinar la teleología que subyace al emprendimiento de los mismos. En otras palabras, se trata de encontrar las razones que motivan al historiador del Derecho a conjurar cierto pasado, por mediación del texto, para acercarse a su instancia: espacios, tiempos, un sin número de elementos jurídicos que emer- 
gen de un contexto determinado para preservar la memoria y la identidad del derecho mismo y del jurista. Esto remite a nuestras palabras:

La concepción de que la Historia del Derecho es una memoria de lo jurídico y del jurista implica una diferenciación con la historia profesional, pues de un lado los objetos de la búsqueda en uno y otro son diversos, y, del otro, la historia no se ocupa de la construcción de identidad disciplinaria del Derecho mismo como sí lo hace la Historia del Derecho mediante la memoria que, unida al análisis, permite una antropología y una etnografía de la cultura jurídica pretérita). Este ejercicio memorístico se logra generalmente por uno de estos tres caminos: i) historizar jurídicamente a los juristas, a los discursos y a los textos no legales, en el pasado de una/la disciplina jurídica (penal, comercial, etc.); ii) historizar jurídicamente la evolución -en su sentido más amplio y menos ideológico - de las instituciones jurídicas de una disciplina jurídica (penal, comercial, etc.); iii) historizar jurídicamente los fenómenos del pasado que hacen (o deberían ser) parte de los estudios de una disciplina jurídica (por ejemplo una norma laboral del pasado de la que tanto habla la dogmática laboral contemporánea).

Entonces, la memoria del derecho y del jurista, supone como misión de identidad disciplinaria, un diálogo permanente con el académico del derecho, independientemente de su área. La Historia del Derecho se perfila así como un ejercicio dialógico entre el iushistoriador con el dogmático, en la construcción de la memoria de su propia disciplina, a partir de un discurso jurídico, profundamente jurídico (Botero, Inédito: 237-279).

En ese sentido, si la finalidad de la iushistoria está relacionada con un proyecto de identidad que confiera propiedad al amplio complejo jurídico, dotándolo, al mismo tiempo, de la suficiente "unidad histórica", de esto se infiere que la historia jurídica debe ser fundamentalmente local o concreta; es decir, sus estudios deben partir del reconocimiento de la diferencia de los objetos consultados dependiendo del (con)texto en que se inscriban. En el fondo, la labor del iushistoriador se dirige a desentrañar el significado latente que trasluce su objeto de estudio, cuidándose de las apariencias que desvían su atención hacia ideales de continuidad histórica (progreso lineal) o de rupturas totales, que han de permanecer incólumes mientras no se acepte, en palabras de Hespanha, que:

Os conceitos interagem em campos semânticos diferentemente estruturados, recebem influências e conotações de outros níveis da linguagem (linguagem corrente, linguagem religiosa, etc.), são diferentemente apropriados em conjunturas sociais ou em debates ideológicos. Por detrás da continuidade aparente na superfície das 
palavras está escondida uma descontinuidade radical na profundidade do sentido. E esta descontinuidade semântica frustra por completo essa pretensão de uma validade intemporal dos conceitos embebidos nas palavras, mesmo que estas permaneçam (Hespanha, 2005 : 27).

\section{Los anacronismos y el espacio-tiempo vital}

\begin{abstract}
A história do direito realiza esta missão sublinhando que o direito existe sempre "em sociedade" (situado, localizado) e que, seja qual for modelo usado para descrever as suas relações com os contextos sociais (simbólicos, políticos, econômicos, etc.), as soluções jurídicas são sempre contingentes em relação a um dado envolvimento (ou ambiente). São, nesse sentido, sempre locais.
\end{abstract}

(Hespanha: $2005: 27$ ).

Del carácter local, específico y relacional de la iushistoria se infiere asimismo el carácter concreto de su objeto de estudio; esto es, el reconocimiento de su peculiaridad intrínseca a pesar de su innegable relación facial. En otras palabras, la justificación de la disciplina iushistórica radica en su preocupación por aprehender realidades jurídicamente relevantes, temporalmente determinadas, espacialmente definidas (o en su caso, definibles) e históricamente apreciables. $\mathrm{Al}$ respecto dice Villegas:

[D] ebe advertirse que al dar inicio a una investigación de naturaleza histórica se debe definir el problema de investigación en un tiempo y espacio bien definidos [...] De esta manera, el problema de investigación circunscrito a un espacio y a un tiempo determinados, termina por constituirse en la brújula que permite al investigador adentrarse en la información disponible, seleccionando lo pertinente y lo relevante para el trabajo propuesto (Villegas, 2009: 15).

Por esto, la iushistoria centra su estudio en espacios-tiempos vitales, en porciones de realidad en la que interactúa un conjunto de elementos que se condicionan recíprocamente y cuyas características definen la formulación de la historia del Derecho; es decir, coadyuvan, de alguna manera, en su perfectibilidad como disciplina jurídica que mira al pasado desde el presente sin desprenderse del futuro. Esto nos conduce a las palabras de Manuel Hespanha, quien ilustra con suficiente precisión el problema del valor facial de los conceptos y de su continuidad terminológica y la discontinuidad semántica:

Embora muitos conceitos ou princípios jurídicos sejam muito mais modernos do que geralmente se supõe, é verdade que há outros que parecem existir, com o sue valor facial (i.e., referidos com as mesmas palavras ou como frases), desde há muito tempo. 
Realmente, conceitos como pessoa, liberdade, democracia, família, obrigação, contrato, propriedade, roubo, homicídio, são conhecidos como construções jurídicas desde os inícios da história do direito europeu. Contudo, se avançarmos um pouco na sua interpretação, logo veremos que, por baixo da superfície da sua continuidade terminológica, existem rupturas decisivas no seu significado semântico (Hespanha, 2005 : 26)..$^{24}$

En cuanto a las modalidades de anacronismos, empecemos afirmando que son fruto de la separación entre el espacio y el tiempo, como por ejemplo creer que lo "jurídico", en cualquier época y cultura, corresponde con lo que aprendimos en la modernidad en tanto éste es el modelo que estructuró nuestro pensamiento, lo que lleva en no pocos casos al iushistoriador que no se ha hecho cargo de sus prejuicios a interrogar al pasado para obligarlo a decir lo que él quiere oír. Para entender esto es indispensable presentar la reflexión que alguna vez hicimos en torno a los anacronismos:

Si se diferencian los anacronismos nominales de los anacronismos de realidades, para permitir - con los cuidados del caso- los primeros y denunciar los segundos, el problema podría tener una solución en la mayoría de los eventos. Por anacronismo nominal entendemos el uso de palabras del presente para actualizar y hacer más comprensibles términos del pasado sin afectar su significado, como por ejemplo hablar de indígenas en vez de "indios"; también concibo por anacronismo nominal el uso de conceptos contemporáneos para visualizar algunas situaciones del pasado que existieron con independencia del prisma con que son observadas [...]. En cambio, por anacronismo de realidades entendemos toda implantación de un fenómeno actual al pasado que no lo tuvo, como creer que Hume, en el siglo XVIII, ya tenía en mente el concepto de "gobierno de los jueces" que tanto defiende un sector muy importante del neoconstitucionalismo contemporáneo (Botero, 2008 : 607-608)

Esto está asociado a reconocer que "el historiador del derecho es hijo de su tiempo y parte de su presente que es siempre su ordenamiento jurídico" (Iglesia, 1996 : 20). Por tanto, el iushistoriador debe hacer un "cuidado de sî" (parafraseando el sentido que a este concepto da Foucault) para evitar los anacronismos de realidades, pero es imposible que sea tan "objetivo" que algo del presente no determine su lectura (esto es, aceptar con prudencia los anacronismos nominales).

Retomando el tema del concepto de espacio-tiempo vital, en el conocimiento ha existido siempre la necesidad de contar con un espacio, lo que permite de alguna manera hablar de una arquitectura del saber en tanto organización y 
diseño del espacio (Botero, 2004). Pero de nada serviría hablar de espacio si no se relaciona con el tiempo, pues, de no hacerse, se cae en un anacronismo (fácilmente de realidades), todo lo cual permite hablar de una cronología crítica (discurso del tiempo) del saber. Ahora bien, frente al espacio-tiempo que determina el camino y cada una de las paradas del mismo, este tiene algo que puede ser construido y algo que pertenece más al campo de lo dado. Frente a lo primero cabe la posibilidad de la propuesta y frente a lo segundo, la necesidad de la descripción.

El espacio-tiempo vital es aquella porción donde una persona, una comunidad, una disciplina, entre otras opciones, subsiste y existe, donde puede establecer parámetros de relación con el otro; de ahí la necesidad de otorgarle sentido al espacio-tiempo y la importancia de la arquitectura y la cronología del saber.

Cabe entonces agregar que el espacio-tiempo vital no puede restringirse, de modo alguno, a una visión colonialista ni mucho menos nacionalsocialista. ${ }^{25}$ Por eso, se propone una nueva conceptualización del espacio-tiempo vital, de manera tal que pueda guiar alguna parte de la acción de los historiadores del Derecho críticos y matizadores así como la lectura del presente trabajo.

Como características de este concepto pueden mencionarse la fraccionabilidad, la necesidad, la mutabilidad, el ser condicionante y estar condicionado, la universalidad y el estar autolimitado en un mínimo. Veamos cada una de estas características.

En primer lugar, el espacio-tiempo vital está compuesto de subespacios; de allí que su primera característica sea la fraccionabilidad en cuanto su composición e, incluso, dependiendo del caso, frente a sus posibilidades de análisis. Quiere decir esto que el espacio-tiempo vital se puede subdividir en múltiples necesidades a satisfacer, elementos que lo componen, análisis que él permite, etc. No obstante, un espacio-tiempo vital no es exactamente igual a la sumatoria de los elementos que lo integran, puesto que además de contar con esos subespacios y subtiempos, se requieren interacciones entre ellos que no pueden ser dirigidas $a$ priori por el científico. Esto recuerda la teoría sistémica, que señala que, si bien un sistema está integrado por ciertos elementos, no basta con reunirlos para que se produzca el sistema, sino que se requieren ciertos tipos de relaciones entre ellos que no pueden ser dirigidos o configurados por el observador, quien, a lo sumo y en condiciones reales, puede simplemente inducirlos pero no garantizar un resultado determinado.

La segunda característica es la necesidad, porque todos los seres humanos, los individuos de una especie, los elementos culturales, etc., buscan o son llevados a relacionarse con un espacio-tiempo concreto y en él se (re)crean como tales y satisfacen sus exigencias para poder existir. 
En tercer lugar, así como los sistemas se autorreferencian de acuerdo con variables, el espacio-tiempo vital comparte su mutabilidad. Lo que hoy puede ser un espacio-tiempo vital en otro escenario o momento podrá ser banal.

Además, como se ha señalado, el espacio-tiempo vital es condicionante y condicionado dentro del interactuar de los individuos o del sistema, por tanto no es unidireccional.

A esto se añade que el espacio-tiempo vital es universal en el sentido de que toda persona, toda familia, todo elemento cultural, etc., concurren en la (re)construcción de un espacio-tiempo vital según sus necesidades, con el cual tendrán que relacionarse. Nadie está exento de poseerlo y, por tanto, de reconstruirlo constantemente.

Junto a ello, el espacio-tiempo vital presenta otra característica: se autolimita en un mínimo. Es decir, que existe un mínimo de espacio-tiempo que no puede ser transgredido, puesto que, de hacerlo, desaparece el individuo o el sistema mismo que de él se soporta, por lo cual, en este aspecto ese mínimo fundamental podría fraccionarse, según el caso, en el análisis que de él se haga o en los elementos que lo componen, pero no admite un fraccionamiento que ponga en duda su propia existencia, puesto que si desaparece ese mínimo desaparece aquello que soporta. También, esta característica se refiere a que el espacio-tiempo, al brindar los aspectos requeridos para la existencia y la subsistencia, se convierte en necesario (asunto que ya se explicó) y sus modificaciones implican reacciones en aquello que de dicho espacio-tiempo depende, por tanto el espacio-tiempo es el mínimo -entendido como condición de existencia y reproducción- de lo que en él se sustenta. De todas formas, las porciones mínimas pueden igualmente estar sujetas a la mutabilidad por lo que es posible encontrar que, en ciertos momentos, el espacio-tiempo vital mínimo será diferente si cambia el espacio o el tiempo, dependiendo del caso.

Finalmente, como última de las características que identifican el espaciotiempo vital debe mencionarse su concreción. Según esta característica, el espacio-tiempo vital es concreto y exige estudios concretos; esto es, nada tiene un espacio-tiempo vital abstracto y no se puede saber sino en relaciones contextuales y temporales claras cuál es el espacio-tiempo vital de algo.

La ventaja de la inclusión cuidadosa de este concepto en la iushistoria la podemos resumir, entre otros, en los siguientes aspectos: I) El espacio tiempo vital implica, además, una reflexión detenida, pausada, analítica de entornos específicos desde enfoques y perspectivas que interactúan en permanente dinamismo. Por tanto, referirse al espacio-tiempo vital en y de la Historia del Derecho significa aludir a las coordenadas espaciales y temporales a partir de las cuales se forja una institución, una norma, un cierto tipo de conocimiento iushistórico, etc., todo lo cual constituye la razón de la memoria del jurista y de lo jurídico, lo que incluso podría ser considerado, siguiendo a Kant en su Crítica 
de la razón pura, como la pregunta por las condiciones de posibilidad de nuestra disciplina y como la petición de credenciales de legitimidad al oficio que ahora nos ocupa. II) Este concepto recuerda la profunda relación existente entre el espacio y el tiempo, no sólo desde la perspectiva de lo estudiado sino, también, desde la perspectiva de la que se estudia. III) El espacio tiempo vital recuerda que el derecho obedece a situaciones concretas en tanto éste es cultural, lo que exige del historiador del derecho asumir sus prejuicios e intentar conectar su objeto de estudio con el (con) texto jurídico que le da valor y sentido, es decir, su vitalidad. Indagar por el espacio-tiempo vital de lo estudiado implica evitar los anacronismos de realidades y usar con prudencia los nominales, logrando igualmente dar vitalidad a su propio espacio-tiempo como iushistoriador. IV) El espacio-tiempo vital conlleva al historiador del Derecho a reconocer que aquello que estudia es un fenómeno mutable, necesariamente relacionado con su contexto temporal y espacial, fraccionable en sus elementos y posibilidades de análisis (según el caso), condicionado y condicionante de otros fenómenos soportados en diferentes espacios-tiempos, concreto, con mínimos fundamentales, etc. V) Desde esta perspectiva, el espacio tiempo vital no es sólo un concepto útil para referirlo al pasado, cuando por ejemplo se estudia una institución jurídica remota, sino incluso para indagaciones en el presente y proyecciones al futuro, como las que surgen cuando se pregunta por el espacio-tiempo vital de la iushistoria (especialmente en América Latina) hoy día, asunto que, por demás, nos remite (como si se tratase esto de un círculo) a las primeras páginas del presente escrito: la consideración de la función de la iushistoria en torno a ser una memoria del jurista y de lo jurídico, basada fundamentalmente en los (con)textos jurídicos; la autonomía relativa de la iushistoria frente a la historiografía profesional, lo que facilita la consolidación disciplinaria de ambas, como requisito previo al diálogo y a la comprensión compleja del derecho como fenómeno cultural; la fraternidad entre estas dos disciplinas que permita el reconocimiento mutuo y, de tal manera, se legitime -sin dejar de lado la construcción disciplinaria- el diálogo; la interdependencia de la historiografía profesional y la iushistoria para comprender (más allá de los horizontes parciales que ofrecen las disciplinas consolidadas) un fenómeno cultural como es el derecho (lo que conduce a la interdisciplinariedad); y demás cosas que al inicio se dijeron.

\section{Notas}

1. Resultado del proyecto de investigación "El espacio-tiempo vital de la Historia del Derecho en la América Latina contemporánea", realizado entre la Universidad de Medellín y el Instituto Tecnológico de Monterrey. El equipo de investigación estuvo integrado por los profesores Andrés Botero Bernal y José Ramón Narváez Hernández y los auxiliares Daniel Zapata Rueda, Leyla Viviana Palacios Díaz, Julián García Ramí- 
rez, Érika Natassia Arroyave López y Paulo Bernardo Arboleda Ramírez. Este escrito es una versión modificada y mejorada de la ponencia realizada en el Primer Encuentro Latino Americano de Historia del Derecho y la Justicia, Puebla (México), el 28 de octubre de 2008.

2. Por historiografía profesional entenderemos la disciplina o (para muchos) ciencia histórica, que tiene su propio estatuto epistemológico y presencia independiente en la universidad.

3. Sobre el carácter de la iushistoria en relación con las disciplinas histórica y jurídica, escribe Martín Morán afirma: "Su encuadramiento como ciencia se puede resumir en tres tendencias: su consideración como ciencia histórica, como ciencia jurídica o como ciencia mixta; en segundo lugar hay aún más diversidad respecto al propio concepto de Historia del Derecho, que está determinado por el concepto que se tenga de Derecho". (Morán Martín, 1999).

4. Las reacciones en contra de la autonomía disciplinaria de la iushistoria respecto de la historiografía profesional provinieron de algunos de los más connotados historiadores generales. Entre ellos, todos defensores de la idea de una "historia total": Marc Bloch, Luciano Febvre, Fernando Braudel y Pedro Vilar. Para Marc Bloch, quien hace alusión a la iushistoria, "la enseñanza y el manual, que con admirables instrumentos de esclerosis, han vulgarizado el nombre de aquella ciencia. Sin embargo, iqué recubre? Una regla de derecho es una norma social, explícitamente imperativa [...] En el sentido estricto de la palabra, el derecho es, pues, la envoltura de realidades en sí mismas demasiado variadas para suministrar con provecho el objeto de un estudio único y no agota ninguna de ellas [...] En suma, la historia del derecho podría no tener existencia aparte, como no fuera la historia de los juristas" (Bloch, 1965).

5. El enfoque interdisciplinario puede considerarse, en esencia, como una propuesta alternativa a los modelos tradicionales de investigación científica. En este caso, las disciplinas no sólo actúan sino que interactúan en continua correspondencia, en inquietante comunicación, en una profunda reciprocidad que admite la complejidad del objeto en estudio y del estudio del objeto mismo. De esta forma, la "interdisciplinariedad emerge en respuesta a problemas definidos en términos de las disciplinas, y habitualmente es promovido como una forma de mejorar la búsqueda disciplinaria del conocimiento de la realidad o la comprensiva aplicación del conocimiento disciplinar a los problemas prácticos" (Mourad, Jr., 1999).

6. En ese orden de ideas, concebir la iushistoria como una disciplina jurídica permitiría de mejor manera el cumplimiento de su función o misión memorística, en un diálogo especialmente con el jurista dogmático. Una historiografía del Derecho pensada como historiografía profesional, tal como se ha venido haciendo por algunos, impide el acercamiento del dogmático que desea saber el/su pasado, aquello que fue jurídico o reputado como tal en su propia área del derecho, pues el discurso disciplinario y la precisión conceptual que requeriría el dogmático del derecho contemporáneo no la encontrará en el historiador. 
7. En similar sentido Palma González (1997) señala que una buena iushistoria (que él denomina "polifacética") es historiográfica; además debe estar abierta a entender el derecho como un fenómeno más allá de lo normativo, lo cual exige que la iushistoria sea abierta a lo social. Teniendo en cuenta lo escrito por Palma, queremos recordar que lo que aquí se discute no es si la iushistoria puede renunciar a la temporalidad de su objeto de estudio (una acepción del término historia), sino otra cosa, el problema disciplinario: ¿la iushistoria, como disciplina que estudia la Historia del Derecho, es parte de la disciplina histórica profesional?

8. Al respecto contamos con el trabajo de Dogan quien expresa que ante la gran dificultad de conocer y construir la propia disciplina, mal se haría si nos aventurásemos sin más a la construcción de fusiones que poco éxito tendrían para la interdisciplinariedad. En consecuencia, conocer y construir disciplina es un requisito básico para los procesos de interdisciplinariedad. Esto, por demás, bien lo trabaja Escobar (2008) quien manifiesta que el derecho es un fenómeno que exige un discurso científico basado en la interdisciplinariedad, el pluralismo en las formas de investigación (como por ejemplo considerar la investigación documental como una forma válida de investigar en la disciplina jurídica, evitando así los prejuicios de los discursos científicos empíricos), no reducir el objeto de la ciencia del derecho a las fuentes formales-estatales y no subordinar la investigación jurídica a la consecución de fines sociales inmediatos. Entonces, fundar disciplina, en el sentido que él propone, conduce a la excelencia académica y a una visión que exigiría la presencia de otras disciplinas (puesto que así la propia ciencia jurídica reconocería, de un lado, que no es la única que puede opinar sobre el derecho y, del otro, el valor académico de las otras disciplinas esperando recibir de esta manera el mismo tratamiento), esto es, una interdisciplinariedad pertinente y posible.

9. Como señalamos en otra ocasión, "la complejidad se funda en dos situaciones: un anhelo y un hecho. El anhelo es interpretar el mundo a partir de modelos disciplinarios en proceso de inter-multi-transdisciplinariedad, y el hecho consiste en que el mundo no está dividido ni fragmentado, y que el aleteo de una mariposa en Pekín puede ori64 ginar un huracán en Florida” (Botero Bernal, 2004 : 172).

10. A esto agregó Vilches, comentando el pensamiento de Zorraquín: "El especialista [de la Historia del Derecho] debe saber trabajar indistintamente ambas disciplinas para que pueda realizar satisfactoriamente su adecuada compenetración, sin hacer de ella una disciplina histórica o jurídica, sino fundiéndolas para alcanzar así una individualidad científica propia” (Vilches Fuentes, 2005 : 353-363).

11. Al respecto, escribe Remedios Morán: "En contraposición, considera (Tomás y Valiente) que la Historia del Derecho ni es ciencia jurídica, ni siquiera un puente entre la ciencia de la historia y la ciencia jurídica, ni una realidad bifronte: es una especialidad de la Historia” (Morán, 1999 : 39). Es importante señalar que Tomás y Valiente defendía la conexión necesaria entre la historiografía y la iushistoria, pero metodológicamente se requiere cierta especificidad jurídica: "De modo semejante a como para hacer historia de la economía es imprescindible emplear métodos propios de la ciencia económica, también la historia del derecho debe emplear junto a las técnicas generales 
propias de cualquier estudio historiográfico otras peculiares derivadas de la naturaleza de su objeto. Por ello el historiador del derecho debe ser, además de historiador, jurista [...] El historiador-jurista deberá, por el contrario, entender y exponer cuáles eran los conceptos jurídicos propios de cada sociedad, lo que suele denominarse la dogmática jurídica de cada momento histórico. Al estudiarla y al exponerla deberá hacerlo poniendo en juego su formación y sensibilidad de jurista" (Tomas, 2001 : 28).

12. Según explica Remedios Morán: "no en el sentido de hacer investigaciones "totalizantes", sino en el sentido de que cada historiador de una rama concreta debe siempre mirar hacia la demás áreas historiables" (Moran, 1999 : 32). Sobre las relaciones entre iushistoria e historia-total (en especial las ventajas que ésta última podría obtener de la primera), no deje de verse: Vilar (1983). Entre otros que parecieran fortalecer el sector de la iushistoria como especialidad de la historiografía general, se encuentran Manuel Hespanha y Carlos Hamilton. El primero, en su texto "Cultura Jurídica Europea”, hace mención a ella con la previa aclaración de su carácter histórico antes que jurídico (Hespanha, 2005). Por su lado, para Hamilton la iushistoria constituye una especialidad de la historiografía general por diferentes motivos: el primero es que, en la definición que el autor hace del objeto de la historiografía y de la iushistoria, anota que el propio objeto de esta última serán los hechos históricos (que son el objeto de la historiografía) pero que sean a su vez jurídicos (o parajurídicos o metajurídicos); de esta forma, el objeto de la iushistoria será el mismo de la historia pero con un condicionante: su ontología jurídica, lo que convertiría a la iushistoria en su especialidad. El segundo motivo reside en que su definición del método -según la cual todo testimonio del pasado será fuente de la historia y objeto de la historiografía- hace que toda fuente de la iushistoria deba ser un testimonio del pasado, sólo con la especialidad de referirse a hechos jurídicos. Finalmente, en su "Manual de historia del derecho" menciona las ciencias afines que le dan auxilio a la iushistoria, a saber: "la historia política, la historia de la filosofía, la historia de las religiones, la historia de la literatura y del arte, la historia de la economía, etc., son ramas especiales de la historia que, como el sujeto y el objeto complejo es común, ejercen mutuas influencias y sirven recíprocamente de fuentes indirectas del conocimiento unas de otras". Entonces, de la misma manera como las historias de estas áreas mencionadas (política, filosofía, etc.) son partes de la historia general, el estudio disciplinario de dichas historias (como la iushistoria) hace parte de la historiografía profesional (Hamilton, 1970).

13. Quien desee profundizar sobre la concepción polifacética, ver: Palma (2009). Ahora bien, ireconocer la temporalidad de la investigación iushistórica impide considerarla como disciplina autónoma -aunque no aislada- de la historia profesional?

14. En contra de esta postura de García: Peset (1978).

15. En el mismo sentido, aludiendo a la función de la memoria como esencia de los estudios en historia del derecho, ha escrito: "(es) aquella potencia del espíritu que construye (presente), sobre el recuerdo (pasado), la conciencia dinámica (futuro) del propio ser" (Pettit, 2003). 
16. En este sentido compartimos la doctrina de la escuela polifacética del derecho, la cual afirma que el iushistoriador no debe renunciar al estudio del contexto sociopolítico del derecho pretérito, en la medida que el ser jurídico es una entidad compleja y no una fragmentación de la realidad. Ver: Palma (1997). Vilches (2005), analizando lo dicho por Zorraquín Becú, señala cuatro grandes inconvenientes de creer que las normas del pasado eran el componente exclusivo del sistema jurídico de ese entonces: i) en toda sociedad hay ignorancia de la ley; por tanto, el estudio de la norma no implica conocer su praxis social; ii) existen movimientos de resistencia a las normas que influyen en el derecho; por tanto, estudiando sólo las normas se pasarían por alto estos movimientos tan importantes para el historiador del derecho; iii) la existencia del desuso o costumbre contra legem que desplaza a varias normas en la práctica y, en ciertas épocas, tuvo efecto derogatorio general; iv) las costumbres, a falta de ley, que integran el Derecho y que no pueden ser ubicadas por medio del mero estudio de las normas.

17. En este punto coincidimos con la propuesta de hacer de la iushistoria una antropología cultural del pasado y, por qué no, del presente, que se defiende en: Clavero (1985), Cappellini (2002). En el primero de estos textos, continuamente citado, el autor pone de manifiesto la importancia de la metodología de la antropología para el iushistoriador, aunque no tanto las composiciones sustantivas de esa disciplina, puesto que, si bien son hermanas gemelas, no son siamesas, y termina afirmando que no es tanto la antropología institucional, sino el derecho, y el derecho común de la modernidad, el que puede ofrecer a la historia europea una adecuada antropología (Clavero, 1985).

18. Al respecto, dijimos: "[...] la memoria concede identidad. El conocer el pasado del fenómeno jurídico logra que este adquiera identidad frente a otros hechos culturales, a la vez que permite entender su interrelación con los mismos" (Botero, 2006 : 16; 2001). En otras palabras, "la Historia del derecho, si estudia a este como realidad técnica, peculiar, irreductible a cualquier otra, pero influida por los sectores de la sociedad más cercanos (lo político, lo cultural, lo económico...) prestará un enfoque enriquecedor al entendimiento intelectual y profundo del Derecho" (Tomás y Valiente, $66 \quad 1979: 42)$.

19. Como, por ejemplo, el uso de imágenes para la investigación social e histórica (Burke, 2001).

20. En primer lugar, no solo es derecho el derecho escrito. En segundo lugar, el iushistoriador trabaja -salvo contadas excepciones- con textos para reconstruir la memoria jurídica. Pero el iushistoriador no debe desdeñar otras fuentes primarias, aunque su principal fuente siga siendo el documento. En tercer lugar, no puede confundirse "fuente primaria" con "fuente del derecho", por lo que el texto jurídico al que acude el iushistoriador no puede reducirse a la norma escrita (Villegas, 2009).

21. Al respecto, considera Hespanha: "É que, de facto, os acontecimentos históricos não estão aí, independentes do olhar do historiador, disponíveis para serem descritos. Pelo contrário, eles são criados pelo trabalho do historiador, o qual seleciona a perspectiva, constrói objectos que não tem uma existência empírica (como curvas de natalidade, tradições literá- 
rias, sensibilidades ou mentalidades) ou cria esquemas mentais para organizar os eventos... A única coisa que o historiador pode verificar são seqüências meramente cronológicas entre acontecimentos; tudo o resto são inferência suas" (Hespanha, 2005 : 34).

22. Ese interés por aprehender la historia del derecho (como la historia general) al margen de procesos lineales, es lo que Hespanha denomina como la tercera estrategia de una historia crítica del derecho. Según él, "A terceira estratégia de uma história crítica do direito é a de insistir no facto de que a história jurídica (como a história em geral) não constitui um desenvolvimento linear, necessário, progressivo, escatológico" (Hespanha, 2005 :34).

23. La historiografía contemporánea es mucho más consciente de que el tiempo es una categoría social y no una línea que evoluciona o progresa hacia estadios superiores. El tiempo, entonces, es una construcción cultural en el que confluyen procesos de larga, mediana y corta duración. En consecuencia, es posible encontrar, según el caso, continuidades y discontinuidades, simultáneamente, en el fenómeno investigado (Braudel, 1980).

24. Sin negar, como lo creemos, que también son posibles discontinuidades terminológicas y continuidades de sentido, como por ejemplo utilizar un término contemporáneo para designar una institución jurídica que proviene de la tradición, dando así una idea falsa de "ruptura" con el pasado.

25. El concepto de espacio vital (Lebensraum) tuvo una derivación teórico-política, expuesta fundamentalmente por el geógrafo alemán Friedrich Ratzel (1844-1904), quien estaba influido por el biologismo y el positivismo de su época. Él consideró que es deber del Estado, a cualquier precio, garantizar a su población un espacio (vital) por medio del cual aquella pudiese satisfacer sus necesidades básicas. También se encuentran los trabajos del sueco Rudolf Kjellen (1864-1922), padre de la geopolítica, quien con este concepto designó las relaciones entre los factores geográficos y el poder estatal en las relaciones internacionales, todo a partir de una visión organicista del Estado. El geógrafo inglés Halford John Mackinder (1861-1947) expuso que Asia central y Europa del Este se habían convertido en el espacio vital del mundo; por tanto, quien los dominara terminaría por controlar el planeta, idea que influyó en el pangermanismo nazista. El alemán Karl Haushofer (1869-1946) aplicó al caso de la Alemania de entreguerras los estudios de Ratzel. En fin, el espacio vital (Lebensraum) tuvo un desarrollo teórico-político, con una fuerte derivación hitleriana y anclada en una estrategia imperialista. No obstante, no todas las derivaciones de este concepto fueron en este orden; incluso, para la misma época del nazismo, el concepto de espacio vital era utilizado en sentidos diferentes, siendo un ejemplo de ello la forma en que el literato y anti-nazista alemán Hermann Broch aludía al espacio vital como el ámbito de construcción del "Yo", acercándose así al psicoanálisis (véase su famosa novela "Die Schuldlosen"). En fin, se quiere aquí desmarcar esas connotaciones políticas e imperialistas de lo que ahora se propone, a partir de una reconstrucción del concepto. 


\section{Referencias}

Bloch, M. (1965). Introducción a la Historia. México: Fondo de Cultura Económica.

Botero Bernal, A. El derecho de los jueces antioqueños en la primera mitad del siglo XIX. Trabajo inédito.

, (2008). "La pluralidad de significados del conservatismo: idesde dónde hablamos?", en: Domínguez Gómez, Eduardo. Historia de las ideologías políticas: proyecto Ágora. Medellín: Canal U y Universidad EAFIT.

, (2006). "Presentación del libro", en: Botero Bernal, Andrés (Editor). Origen del Constitucionalismo Colombiano: Ponencias del III Seminario Internacional de Teoría General del Derecho. No. 1. Medellín: Editorial Universidad de Medellín.

, (2004). "Introducción", en: Botero Bernal, Andrés (Editor). Naturaleza y Cultura: Una mirada interdisciplinaria. Medellín. Editorial Biogénesis. , (2004). "Nuevos paradigmas científicos y su incidencia en la investigación jurídica”. Revista de Derecho, No. 21.

, (2001). "Justicia a la memoria y al recuerdo". Revista Universidad de San Buenaventura. No. 14.

Braudel, F. (1980). La historia y las ciencias sociales. Madrid: Alianza.

Burke, P. (2001). Visto y no visto: el uso de la imagen como documento histórico. Barcelona: Crítica.

Cappellini, P. (2002). "Il codice eterno: La Forma - Codice e i suoi destinatari: morfologie e metamorfosi di un paradigma della modernità", en: Cappellini, P. e Sordi, B. Codici: Una riflessione di fine millennio. Milano: Giuffrè.

Capra, F. (2007). "Complexity and Life". Systems research and behavioral science Syst. Vol. 24.

Clavero, B. (1985). "Historia y antropología: por una epistemología del derecho moderno", en: Cerda y Ruiz-Funes, Joaquín, y Salvador Coderch, Pablo. (ed.). I Seminario de historia del derecho y derecho privado: nuevas técnicas de investigación. Bellaterra (Barcelona): Universidad Autónoma de Barcelona.

Dogan, M. (2001). "La ciencia política y las otras ciencias sociales". Trad. N. Lagares et al, en: R. E. Goodin y H.D. Klingemann, Nuevo manual de Ciencia Política. Tomo 1. Madrid: Ediciones Istmo. 
Escobar Córdoba, F. (2008). "Una defensa pluralista de la investigación jurídica", en: Criterio Jurídico, Vol. 8, 2.

García-Gallo, A. (1971). Metodología de la Historia del Derecho Indiano. Santiago de Chile: Editorial Jurídica de Chile.

Grossi, P. (2003). Prima Lezione di diritto. Bari: Laterza.

Hamilton, C. (1970). Manual de Historia del Derecho. Santiago de Chile: Editorial Jurídica de Chile.

Hespanha, A. M. (2005). Cultura Jurídica Européia: Síntese de um milênio. Florianópolis: Fundação Boiteux.

Iglesia Ferreirós, A. (1996). La creación del Derecho: una historia de la formación de un derecho estatal español. Tomo 1. Madrid: Marcial Pons.

Latorre, A. (1985). Introducción al Derecho. Barcelona: Ariel.

Lecuona, E. (2006). "Historia del Derecho y Ciencia Jurídica en los Estados Unidos de América: El debate en torno al Historicismo Crítico de Robert W. Gordon”. Revista de Estudios Histórico-Jurídicos, No. 28, pp. 589-611. Obtenido el 26 junio de 2007, en: http://www.scielo.cl/scielo.php?script $=$ sci arttext\&pid $=$ S0716-54552006000100018\&lng $=\mathrm{es} \& n r m=$ iso $>$.

Morán Martín, R. (1999). Materiales para un curso de historia del derecho español. Tomo I. Madrid: Universidad Nacional de Educación a Distancia.

Narváez Hernández, J. R. (2003). "Recibir y concebir el derecho en la historia: una propuesta a la base de la función de la historia del derecho". Revista Telemática de Filosofía del Derecho, obtenido el 12 junio de 2007, en: www.filosofiayderecho.com/rtfd/index.htm.

Palma González, E. E. (2009). "Pasado, presente y futuro de la historia del derecho en Chile", Forum Historiae Iuris. Obtenido el 21 de abril de 2009, en: http://www.forhistiur.de/zitat/0903palma.htm

, (1997). "Reflexiones en torno a una concepción polifacética para una historia del derecho de los siglos XIX y XX". Revista Ius et Praxis, Año 3, No. 2.

Peset, M. (1978). "Prólogo", en: Pérez Martín, Antonio y Scholz, JohannesMichael. Legislación y jurisprudencia en la España del Antiguo Régimen. Valencia: Universidad de Valencia. 
Petit, C. (2005). "De la historia a la memoria. A propósito de una reciente obra de historia universitaria". Cuadernos del Instituto Antonio de Nebrija de Estudios sobre la Universidad, No. 8.

, (2003). "Abogados, historias, memoria. Informe gráfico sobre la abogacía española", en: Alpa, Guido e Danovi, Remo (a cura di). Un progetto di ricerca sulla storia dell'avvocatura. Bologna: Società editrice Il Mulino.

Mourad, R. P. (1997). "Postmodern Interdisciplinarity". The Review of Higher Education. Vol. 20 (2). Obtenido el 10 de octubre 2007, en: http://www.fceia. unr.edu.ar/labinto/facultad/decanato/secretarias/desarr_institucional/biblioteca_digital/articulos_pdf_biblioteca_digital/bd_pe_T-33.pdf.

Tomás y Valiente, F. (2001). Manual de Historia del Derecho español. Madrid: Editorial Tecnos.

, (1979). La historiografía jurídica en la Europa continental $\overline{\text { (1900-1975). LXXV }}$ años de evolución jurídica en el mundo: historia del derecho y derecho comparado. Volumen II, México: UNAM.

Vilches Fuentes, H. (2005). "La teoría de la historia del derecho en Ricardo Zorraquín Becú”. Revista de Estudios Histórico - Jurídicos, 27.

Villegas del Castillo, C. (2009). "Historia y Derecho: La interdisciplinariedad del derecho y los retos de la historia del Derecho". Revista de Derecho Público. No. 22.

Zorraquín Becú, R. (1978). Apuntes para una teoría de la historia del derecho. Buenos Aires: UBA. 